\title{
KEPEMIMPINAN KEPALA SEKOLAH YANG EFEKTIF STUDI KASUS DI SDK ST. YUSUF MADIUN
}

\author{
Ely Sabhet Retno Palupi, Ola Rongan Wilhelmus ${ }^{*}$ \\ STKIP Widya Yuwana \\ elysabhetretno752@gmail.com \\ *) penulis korespondensi, olarongan@widyayuwana.ac.id
}

\begin{abstract}
The teacher has a duty as an educator and also as a guide for students in the learning process. Therefore, teachers must be aware of their position as professional educators and have high performance. Teacher performance will be optimal if it is supported by good leadership from the principal as well as good and adequate work facilities and infrastructures. Principal leadership is one of the determining factors to improve teacher performance in the school. As a leader, the principal should have an ability to influence everyone, especially the teachers, so that they can work better for the realization of educational goals. This study explores the theme of the Influence of Principal Leadership on Teacher Performance. The purpose of this study is to analyze the extent to which the principal's leadership influences on the performance development of teachers in schools. This study used qualitative research methods. Data collection was carried out by online interview techniques through the WhatsApp application and also directly or face to face interview. Respondents in this study consisted of seven teachers, namely homeroom teachers I-VI and student affair section at SDK St. Yusuf Madiun.
\end{abstract}

Keywords: Leadership, Principal, Teacher Performance.

\section{PENDAHULUAN}

Pendidikan yang berkualitas tidak terlepas dari peran kepala sekolah sebagai pemegang kebijakan untuk menciptakan suasana kondusif di sekolah demi terlaksananya proses pendidikan yang efektif dan efisien. Setiap pemimpin atau kepala sekolah bertanggungjawab dalam mengarahkan serta memonitoring kinerja guru agar kinerjanya dapat maksimal.

Segala penyelenggaran pendidikan mengarah pada usaha meningkatkan mutu pendidikan dan hal ini sangat dipengaruhi oleh guru melalui pelaksanaan tugasnya secara profesional. Kepala sekolah dituntut melakukan supervisi atas pelaksanaan tugas guru. Hal ini, memungkinkan kegiatan operasional belajar dan mengajar yang dilakukan oleh guru dapat berlangsung dengan baik. Kegiatan 
supervisi perlu dilakukan oleh kepala sekolah, sebab sering terjadi guru tidak bisa melaksanakan kinerjanya dengan baik karena kepala sekolah belum dapat membangkitkan semangat kinerja para guru dan masih banyak guru yang kurang kompeten (Didi Pianda 2018:8).

Selain itu, keteladanan kepala sekolah juga turut memengaruhi tingkat kedisiplinan guru yang tercermin dari ketaatan terhadap waktu dan kedisiplinan guru menjalankan tugasnya. Keteladanan merupakan salah satu karakteristik penting bagi keberhasilan seorang pemimpin (Haluti\&Sudirman, 2018: 42).

Tujuan dari tulisan ini adalah: 1) mengekspolarasi bagaimana kepemimpinan kepala sekolah di SDK St. Yusuf di Kota Madiun dijalankan; 2) mengekspolarasi sejauh mana kepedulian, kesediaan dan profesionalitas kepala sekolah membantu meningkatkan kinerja para guru di SDK St. Yusuf di Kota Madiun; 3) mengekspolarasi pengaruh kepemimpinan kepala sekolah terhadap kinerja guru di Sekolah Dasar Katolik St. Yusuf di Kota Madiun.

Penelitian ini menggunakan metode kualitatif. Metode penelitian kualitatif adalah sebuah metode penelitian yang berlandaskan pada filsafat postpositivisme dan digunakan untuk meneliti kondisi obyek yang alamiah, dimana peneliti berperan sebagai instrumen kunci. Teknik pengumpulan data dilakukan melalui wawancara mendalam serta analisis data bersifat induktif atau kualitatif. Hasil penelitian kualitatif mengarah pada makna satuan data lapangan (Sugiyono 2017:9). Tulisan ini diharapkan bermanfaat bagi semua pihak, terkhusus bagi Kepala Sekolah SDK St. Yusuf Madiun, para guru SDK St. Yusuf Madiun dan peneliti selanjutnya.

\section{PEMBAHASAN}

\subsection{Pengertian Kinerja Guru}

Lembaga pendidikan sebagai sebuah lembaga organisasi dipandang sebagai suatu sistem dan unit kerja yang terdiri dari kelompok-kelompok orang yang mengemban berbagai tugas dan tanggung jawab serta terkoordinasi untuk memiliki konstribusi dalam mencapai tujuan pendidikan (Supardi, 2019:41).

Kinerja guru sendiri merupakan sebuah kemampuan yang dimiliki guru dalam melaksanakan tugas pembelajaran serta tanggungjawab atas peserta didik dengan tujuan meningkatkan prestasi belajar peserta didik. Kinerja guru merupakan sebuah kondisi yang menunjukkan kemampuan seorang guru dalam menjalankan tugasnya termasuk ketrampilan melakukan aktivitas pembelajaran di sekolah (Supardi 2019:54).

Supardi (2019:40) mengatakan bahwa kinerja guru merupakan sebuah kemampuan dan keberhasilan guru melaksanakan tugas pembelajaran yang ditunjukkan dengan beberapa indikator antara lain: 1) kemampuan menyusun rencana dan program pembelajaran; 2) kemampuan melaksanakan pembelajaran; 
3) kemampuan mengadakan hubungan antar pribadi; 4) kemampuan melaksanakan penilaian; 6) kemampuan melaksanakan program remedial.

Kinerja guru dapat dilihat secara jelas melalui pengajaran yang dilakukan guru dan prestasi belajar peserta didik. Kinerja guru yang baik akan menghasilkan sebuah prestasi belajar yang baik bagi peserta didik. Menurut Glasman (1986:12) dalam Supardi (2019:55) mengatakan bahwa kinerja yang baik akan terlihat dari hasil yang diperoleh dari penilaian peseta didik.

Tabel 1. Pengertian mengenai kinerja guru

\begin{tabular}{|c|l|c|c|c|}
\hline \multicolumn{5}{|c|}{ Indeks } \\
\hline Kode & \multicolumn{1}{|c|}{ Jawaban } & Informan & Jumlah & Presentase \\
\hline 2a & Kualitas kerja guru & I1, I2, I3, I7 & 4 & $57,14 \%$ \\
\hline 2b & $\begin{array}{l}\text { Kegiatan yang dilakukan guru dalam } \\
\text { mencapai tujuan yang sudah direncanakan }\end{array}$ & I4 & 1 & $14,28 \%$ \\
\hline 2c & Hasil kerja guru & I5 & 1 & $14,28 \%$ \\
\hline 2d & $\begin{array}{l}\text { Sesuatu yang harus dilakukan guru selaku } \\
\text { guru professional sesuai tuntutan } \\
\text { kurikulum }\end{array}$ & I6 & 1 & $14,28 \%$ \\
\hline
\end{tabular}

Para informan memiliki jawaban yang variatif mengenai pemahaman tentang kinerja guru. Terdapat 4 jawaban yang diungkapkan para informan mengenai pemahaman tentang kinerja guru yaitu kinerja guru sebagai kualitas kerja guru (57,14\%), kegiatan yang dilakukan guru dalam mencapai tujuan pembelajaran yang sudah direncanakan (14,28\%), hasil kerja guru(14,28\%) dan kinerja guru adalah pekerjaan yang harus dilakukan guru selaku guru professional sesuai tuntutan kurikulum (14,28\%). Diantara 4 jawaban itu kebanyakan para informan menjawab bahwa kinerja guru adalah kualitas kerja guru. Maka dapat ditarik kesimpulan bahwa sebagian besar informan menjawab kinerja guru adalah kualitas kerja guru, dan sebagian kecil menyebutkan bahwa kinerja guru adalah kegiatan yang dilakukan guru dalam mencapai tujuan yang sudah direncanakan atau hasil kerja guru.

\subsection{Motivasi Kerja Kepala Sekolah}

\subsubsection{Kepala Sekolah sebagai Motivator}

Kepala sekolah diwajibkan untuk menjadi motivator dan harus memiliki sebuah strategi yang tepat untuk memberikan motivasi kepada tenaga pendidikan dalam menjalankan tugas dan fungsinya. Motivasi ini dapat bertumbuh melalui pengaturan lingkungan fisik, pengaturan suasana kerja, disiplin, dorongan, penghargaan secara efektif dan penyediaan berbagai sumber belajar (Mulyasa, 2011:120). 
Pengaturan lingkungan fisik ini mengarah kepada lingkungan yang kondusif dan dapat menumbuhkan motivasi tenaga kependidikan dalam melaksanakan tugasnya. Maka, kepala sekolah perlu membangkitkan motivasi tenaga kependidikan agar dapat melaksanakan kinerjanya dengan maksimal (Mulyasa, 2011:120).

Pengaturan suasana kerja yang tenang dan menyenangkan akan mempengaruhi bangkitnya kinerja tenaga kependidikan. Kepala sekolah perlu menciptakan hubungan kerja yang harmonis dengan para tenaga kependidikan (Mulyasa, 2011:120).

Tabel 2. Motivasi kerja kepala sekolah bagi guru

\begin{tabular}{|c|c|c|c|c|}
\hline \multicolumn{5}{|c|}{ Indeks } \\
\hline Kode & Jawaban & Informan & Jumlah & Presentase \\
\hline $4 a$ & $\begin{array}{l}\text { Kepala sekolah memberi motivasi pada saat rapat } \\
\text { rutin bulanan }\end{array}$ & I1, I7 & 2 & $28,57 \%$ \\
\hline $4 \mathrm{~b}$ & $\begin{array}{l}\text { kepala sekolah memberikan semangat pagi lewat } \\
\text { ucapan selamat pagi }\end{array}$ & $\mathrm{I} 2$ & 1 & $14,28 \%$ \\
\hline $4 \mathrm{C}$ & Memberi nasehat-nasehat & I2, I7 & 2 & $28,57 \%$ \\
\hline $4 d$ & $\begin{array}{l}\text { Dimotivasi untuk terus belajar memberikan yang } \\
\text { terbaik bagi siswa terutama dalam hal IT }\end{array}$ & I3 & 1 & $14,28 \%$ \\
\hline $4 \mathrm{e}$ & $\begin{array}{l}\text { Mendapat semangat dan motivasi dari kepala sekolah } \\
\text { yang sifatnya membangun }\end{array}$ & I4 & 1 & $14,28 \%$ \\
\hline $4 \mathrm{f}$ & $\begin{array}{l}\text { Memberikan motivasi melalui kata-kata atau } \\
\text { keteladanan yang baik }\end{array}$ & I5 & 1 & $14,28 \%$ \\
\hline $4 g$ & $\begin{array}{l}\text { Memberi kepercayaan kepada guru sehingga guru } \\
\text { berkembang }\end{array}$ & I6 & 1 & $14,28 \%$ \\
\hline
\end{tabular}

Berdasarkan analisa diatas mengenai sejauh mana motivasi kepala sekolah meningkatkan kinerja para guru. Para informan mengatakan bahwa kepala sekolah memberi motivasi pada saat rapat rutin bulanan (28,57\%) dan kepala sekolah senantiasa memberikan nasehat-nasehat kepada para guru (28,57\%). Dapat ditarik kesimpulan mengenai motivasi kepala sekolah meningkatkan kinerja para guru adalah kepala sekolah sudah memberikan motivasi kerja bagi para guru dalam meningkatkan kinerja. Sebagai seorang pemimpin, kepala sekolah sudah menciptakan suasana yang baik dan kondusif di sekolah serta memiliki kepedulian yang tinggi terhadap para guru.

\subsubsection{Kepemimpinan Kepala sekolah}

Kepemimpinan merupakan hal yang paling penting dalam manajemen berbasis sekolah. Kepemimpinan diartikan sebagai kegiatan untuk mempengaruhi orang-orang dan diarahkan pada pencapaian tujuan organisasi. Sutisna dalam Mulyasa (2003:107) mengartikan kepemimpinan sebagai proses mempengaruhi 
kegiatan seseorang atau kelompok orang dalam usaha mencapai tujuan tertentu sebagaimana di inginkan.

Menurut John Stott (2009:5) kepemimpinan di sekolah Katolik yang dijalankan oleh kepala sekolah bertujuan memberi sebuah arah dan jalan tertentu untuk menginspirasi orang lain. Seorang pemimpin ialah seorang yang mampu memberikan pengaruh baik bagi komunitasnya.

Soepardi 1988 dalam Mulyasa (2003:107) mendefinisikan kepemimpinan sebagai kemampuan untuk menggerakkan, mempengaruhi, memotivasi, mengajak, mengarahkan, menasehati, membimbing, memerintah, melarang, dan menghukum, serta membina dengan maksud agar manusia sebagai media manajemen mau bekerja dalam rangka mencapai tujuan administrasi secara efektif dan efesien. Kepemimpinan di sekolah Katolik juga diharapkan memiliki kemampuan yang sama dalam menjalankan tugasnya sebagai kepala sekolah di sekolah Katolik dan mencapai tujuan sekolah Katolik sebagaimana telah ditetapkan secara bersama.

Kepala sekolah adalah pemimpin yang memiliki peran besar bagi perkembangan mutu pendidikan di sekolah Katolik. Sebagai seorang pemimpin, kepala sekolah hendaknya memiliki kemampuan untuk menolong bawahannya untuk memahami tujuan sekolah yang ingin di capai. Dalam dunia pendidikan, kepala sekolah Katolik diharapkan mampu membangkitkan semangat kerja yang tinggi bagi guru dan menciptakan suasana kerja yang menyenangkan, aman dan dijiwai oleh iman Katolik dan injil Yesus. Sebagai seorang pemimpin kepala sekolah harus mampu mengembangkan staf guru untuk bertumbuh dalam kepemimpinannya di sekolah Katolik. Profesionalitas guru di sekolah banyak ditentukan oleh kualitas kepemimpinan kepala sekolah (Lazaruth Soeadji, 1984:60).

Tabel 3. Pandangan guru terkait keteladanan kepala sekolah (pemimpin)

\begin{tabular}{|l|c|c|c|}
\hline \multicolumn{3}{|c|}{ Indeks } \\
\hline \multicolumn{1}{|c|}{ Jawaban } & Informan & Jumlah & Presentase \\
\hline Sangat bagus & I1, I2, I3, I4, I5, I6, I7 & 7 & $100 \%$ \\
\hline Disiplin & I1, I3, I4 & 3 & $42,85 \%$ \\
\hline Terbuka & I1 & 1 & $14,28 \%$ \\
\hline Mendukung kemajuan karyawan & I1 & 1 & $14,28 \%$ \\
\hline Bijaksana & I2, I7 & 2 & $28,57 \%$ \\
\hline Tegas & I7 & 1 & $14,28 \%$ \\
\hline
\end{tabular}

Berdasarkan analisa diatas mengenai pandangan informan tentang keteladanan kepala sekolah. Para informan mengatakan bahwa kepemimpinan dan keteladanan kepala sekolah sangat bagus (100\%), kepala sekolah sangat disiplin (42,85\%) dan kepala sekolah sangat bijaksana (28,57\%). Kesimpulan mengenai 
keteladanan kepemimpinan kepala sekolah bahwa kapala sekolah senantiasa memberikan teladan yang sangat baik bagi para guru. Kepala sekolah senantiasa bertindak dan memberi contoh yang baik bagi bawahannya. Keteladanan kepala sekolah ini sangat berpengaruh terhadap kinerja guru sebagai bawahannya yang senantiasa terdorong untuk melakukan hal-hal baik sebagaimana dikerjakan dan diperlihatkan oleh kepala sekolah.

\subsubsection{Upaya Kepala Sekolah untuk Meningkatkan Profesionalisme Guru}

Manajemen adalah proses perencanaan, mengorganisasikan, melaksanakan, memimpin dan mengendalikan anggota organisasi dan mendayagunakan sumber daya organisasi untuk mencapai tujuan yang ditetapkan. Dalam melakukan peran dan tugasnya, kepala sekolah hendaknya memiliki strategi untuk memberdayakan tenaga kependidikan melalui kerjasama, memberikan kesempatan kepada para guru untuk meningkatkan profesinya dan mendorong keterlibatan seluruh tenaga pendidikan dalam kegiatan yang menunjang program sekolah (Mulyasa, 2011:103).

Kepala sekolah melakukan pekerjaanya secara konstruktif, kreatif, delegatif, integratif rasional, objektif, pragmatis, keteladanan, disiplin, adaptable dan fleksibel. Konstruktif diartikan sebagai upaya meningkatkan profesionalisme tenaga pendidik di sekolah. Kepala sekolah hendaknya berusaha mendorong dan membina setiap tenaga pendidik agar berkembang secara optimal dalam melaksanakan tugas yang diemban. Kepala sekolah sebagai inovator hendaknya mampu mencari, menemukan dan melaksanakan berbagai pembaharuan di sekolah (Mulyasa, 2011:118).

Kepala sekolah hendaknya mencari cara-cara baru dan kreatif dalam meningkatkan profesionalisme guru dalam menjalankan tugasnya, agar guru dapat memahami apa yang disampaikan demi dapat mencapai tujuan sekolah sesuai visi dan misi sekolah (Mulyasa, 2011:118). Delegatif artinya kepala sekolah berupaya meningkatkan profesionalisme tenaga guru dengan cara mendelegasikan tugas kepada para guru sesuai dengan deskripsi tugas, jabatan dan sesuai kemampuan (Mulyasa, 2011:118).

Integratif artinya dalam meningkatkan profesionalisme guru di sekolah, kepala sekolah berupaya mengintegrasikan semua kegiatan sehingga menghasilkan sinergi untuk mencapai tujuan sekolah dengan baik (Mulyasa, 2011:1118). Rasional dan obyektif artinya kepala sekolah berusaha meningkatkan kemampuan guru untuk bertindak secara rasional dan objektif (Mulyasa, 2011:119). Pragmatis artinya kepala sekolah hendaknya berusaha menetapkan kegiatan dan target yang perlu dicapai para guru berdasarkan kemampuan nyata yang dimiliki oleh setiap guru (Mulyasa, 2011:119). 
Adaptabel dan fleksibel. Artinya dalam meningkatkan profesionalisme guru, kepala sekolah perlu beradaptasi dan bersikap fleksibel dalam menghadapi situasi baru dan menciptakan suasana kerja yang menyenangkan dan memudahkan para guru dalam menjalankan tugasnya (Mulyasa, 2011:119).

Tabel 4. Upaya Kepala Sekolah Meningkatkan Profesionalitas Guru

\begin{tabular}{|l|c|c|c|}
\hline \multicolumn{4}{|c|}{ Indeks } \\
\hline \multicolumn{1}{|c|}{ Jawaban } & Informan & Jumlah & Presentase \\
\hline Mengikuti webinar & I1, I2, I4, I5 & 4 & $57.14 \%$ \\
\hline Mengikuti diklat & I2 & 1 & $14,28 \%$ \\
\hline Workshop & I2 & 1 & $14,28 \%$ \\
\hline Pendidikan khusus bagi guru & I2 & 1 & $14,28 \%$ \\
\hline Pelatihan pemanfaatan aplikasi & I3,I7 & 2 & $28,57 \%$ \\
\hline Pelatihan pembuatan video pembelajaran & I3 & 1 & $14,28 \%$ \\
\hline Mengikuti KKG & I4, I5 & 2 & $28,57 \%$ \\
\hline pelatihan kursus pramuka dan kerawitan & I6 & 1 & $14,28 \%$ \\
\hline
\end{tabular}

Berdasarkan analisa di atas mengenai upaya kepala sekolah meningkatkan profesionalitas guru para informan mengatakan bahwa telah mengikuti banyak kegiatan untuk meningkatkan profesionalitas guru. Kegiatannya tersebut meliputi webinar (57.14\%), mengikuti pelatihan pemanfaatan aplikasi (28,57\%), mengikuti kelompok kerja guru (KKG) (28,57\%) dll. Dalam hal ini dapat ditarik kesimpulan bahwa kepala sekolah senantiasa berupaya mengadakan berbagai bentuk kegiatan dengan tujuan meningkatkan profesionalisme guru dengan cara mengadakan kegiatan-kegiatan pengembangan pengetahuan atau ketrampilan bagi guru.

\subsubsection{Kepedulian Kepala Sekolah Membantu Guru Mengatasi Kesulitan}

Kepala sekolah diharapkan memberikan bimbingan konseling dan kesempatan bagi para guru untuk sharing mengenai masalah yang dihadapi dan memberikan bimbingan kepada guru terkait kegiatan pembelajaran dan profesionalisme guru. Pembicaraan individual ini merupakan teknik yang sangat efektif dalam strategi pembinaan tenaga kependidikan (Mulyasa 2011:114).

Kepala sekolah diharapkan mampu menciptakan iklim yang baik dan kondusif agar tenaga pendidik dapat melaksanakan tugasnya dengan baik secara proporsional dan profesional. Untuk menciptakan kegiatan belajar dan mengajar yang baik, kepala sekolah perlu berusaha menyiapkan sarana prasarana dan sumber belajar yang baik bagi guru untuk melaksanakan tugasnya dalam mengajar dengan baikdan memberikan kemudahan belajar bagi siswa di sekolah (Mulyasa 2011:99). 
Tabel 5. Kepedulian kepala sekolah terhadap guru

\begin{tabular}{|c|l|c|c|c|}
\hline \multicolumn{5}{|c|}{ Indeks } \\
\hline Kode & \multicolumn{1}{|c|}{ Jawaban } & Informan & Jumlah & Presentase \\
\hline 14a & Kepala sekolah selalu welcome & I1, I2, I4, I5 & 4 & $57,14 \%$ \\
\hline 14b & $\begin{array}{l}\text { Kepala sekolah langsung menanggapi } \\
\text { dan selalu memberikan solusi }\end{array}$ & $\begin{array}{c}\text { I1, I2, I3, I4, I5, } \\
\text { I6, I7 }\end{array}$ & 7 & $100 \%$ \\
\hline 14c & Mengusahakan kouta bagi para guru & I7 & 1 & $14,28 \%$ \\
\hline
\end{tabular}

Berdasarkan analisa diatas mengenai kepedulian kepala sekolah dalam membantu para guru mengatasi kesulitan dalam pembelajaran, para informan mengatakan bahwa selama ini kepala sekolah selalu terbuka (57,14\%). Selanjutnya, ketika para guru mengalami kesulitan dalam pembelajaran kepala sekolah langsung menanggapi dan memberikan solusi bagi para guru (100\%). Terkait hal ini dapat diambil kesimpulan bahwa kepala sekolah memiliki kepedulian tinggi bagi para guru dan kepala sekolah senantiasa bersedia untuk membantu para guru dalam menghadapi kesulitan atau masalah dalam proses belajar mengajar di sekolah serta memberi solusinya.

\section{KESIMPULAN}

Kepemimpinan kepala sekolah di SDK St. Yusuf dalam meningkatkan kinerja guru sangat baik. Kepala sekolah sangat peduli terhadap para guru melalui motivasi, keteladanan dan kepedulian. Kepala sekolah membuat para guru semakin semangat dalam melakukan pekerjaannya. Setiap pagi, kepala sekolah senantiasa memberikan sapaan-sapaan hangat yang memberikan dorongan dan energi yang baik bagi para guru, sehingga dapat menjadi lebih semangat dalam bekerja.

Kepala sekolah memiliki kepeduliaan yang sangat tinggi bagi para guru. Kepala sekolah sangat terbuka dan senantiasa membantu para guru setiap menghadapi permasalahan atau kesulitan. Kepala sekolah juga memberikan solusi-solusi bagi setiap permasalahan atau kesulitan yang dihadapi oleh para guru. Dengan demikian, kegiatan belajar mengajar dapat berjalan dengan baik.

Kepa sekolah mempunyai beberapa program untuk meningkatkan kinerja para guru untuk meningkatkan profesionalitasnya, yaitu dengan mengadakan seminar, workshop pengembangan profesi, diklat, pendidikan khusus bagi guru, pelatihan pemanfaatan aplikasi dan lain-lain. Kepala sekolah senantiasa mendukung para guru untuk berkembang melalui kegiatan-kegiatan yang diadakan.

Kepemimpinan kepala sekolah sangat mempengaruhi kinerja guru. Sebagai seorang pemimpin yang efektif, kepala sekolah memberikan motivasi, menentukan arah dan menjadi teladan yang baik bagi para guru. Dengan adanya motivasi, keteladanan, dan kepedulian kepala sekolah yang tinggi, maka para guru 
akan semakin terdorong untuk bekerja secara profesional dan sesuai dengan prosedur yang mengarah pada pencapaian tujuan sekolah.

\section{DAFTAR PUSTAKA}

Ali, Erdi., 2013, Merajut Jiwa Kepemimpinan. IPB Press: Bogor.

Haluti, A \& Sudirman, A., (2018), Hubungan Keteladanan Kepala Sekolah Dengan Disiplin Kinerja Guru Di Smp Negeri Se-Kecamatan Bunta. Jurnal Pendidikan Glasser, 2(2), 41-47.

Stott, John., 2009, Kepemimpinan Kristen. Tenggilis Mejoyo: Surabaya.

Lazaruth, Soewadji., 1984, Kepala Sekolah dan Tanggungjawabnya. Kanisius: Yogyakarta.

Mulyasa, E., 2003, Manajemen Berbasis Sekolah. PT Remaja Rosdakarya: Bandung. , 2011, Menjadi Kepala Sekolah yang Profesional. PT Remaja Rosdakarya: Bandung.

Pianda, Didi., 2018, Kinerja Guru. Jawa Barat: CV Jejak.

Supardi., 2019, Kinerja Guru. PT Raja Grafindo: Jakarta.

Susanto, A., (2016), Manajemen Peningkatan Kinerja Guru: Konsep, Strategi, dan Implementasinya. Jakarta: Prenadamedia Group. 